\title{
Results of Russian geomagnetic observatories in the 19th century: magnetic activity, 1841-1862
}

\author{
H. Nevanlinna and L. Häkkinen \\ Finnish Meteorological Institute, P.O. Box 503, 00101 Helsinki, Finland \\ Received: 4 January 2010 - Revised: 17 March 2010 - Accepted: 31 March 2010 - Published: 12 April 2010
}

\begin{abstract}
Hourly (spot readings) magnetic data (H- and Dcomponents) were digitized from Russian yearbook tables for the years 1850-1862 from four observatories. The pdf pictures for digitization were taken by a normal digital camera. The database obtained consists of about 900000 single data points. The time series of hourly magnetic values reveal slow secular variations (declination only) as well as transient and regular geomagnetic variations of external origin. The quality and homogeneity of the data is satisfactory. Daily Ak-indices were calculated using the index algorithm that has been earlier applied to 19th century data from Helsinki (Finland) as well as modern magnetic observatory recordings. The activity index series derived from the Russian data is consistent with earlier activity index series for 1850-1862. The digitized index data series derived in this study was extended back to 1841 by including magnetic $C 9$ activity index data available from a Russian observatory (St. Petersburg). Magnetic data rescued here is well suitable for various reconstructions for studies of the long-term variation of the space weather in the 19th century.
\end{abstract}

Keywords. Geomagnetism and paleomagnetism (Time variations, diurnal to secular) - History of geophysics (Geomagnetism and paleomagnetism)

\section{Introduction}

The history of Russian geomagnetic network goes back to the 1820 s when a resurgence of interest in geomagnetism took place in the international scientific community. The leading Russian scientist in the field of geomagnetism and meteorology was Adolf Kupffer (1799-1865), a German-Latvian born physicist, who founded the first magnetic observato-

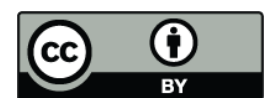

Correspondence to: H. Nevanlinna (heikki.nevanlinna@fmi.fi) ries of Russia in Kazan and in St. Petersburg in 1829 (Cawood, 1977; Malin and Barraclough, 1991). Kupffer was influenced by outstanding scientists of his time and he had personal connections with them. These were e.g., Arago in Paris, von Humboldt in Berlin and Gauss in Göttingen, all of them had contributed important observational and theoretical innovations in geomagnetism. Kupffer had close cooperation with them in various aspects of geomagnetic observations. He was also a member of the famous Göttingen Magnetic Union and a similar enterprise organised by von Humboldt in the 1830s (Soffel, 2006). The Union introduced to the world geomagnetic community standardised equipment and observational routines for recording magnetic variations in the observatory conditions.

Kupffer moved to St. Petersburg in 1830 and later in the 1830s he organised the establishment of magnetic observatories at several locations by a suggestion of von Humboldt (see Fig. 1, Tables 1 and 2). Magnetic observations were done several times daily. This work developed in a more comprehensive observational programme in 1841 when regular magnetic observations started at four observatories: St. Petersburg, Ekaterinburg (Catherinburg), Barnaul and Nertchinsk mainly on hourly base (see e.g., Malin and Barraclough, 1991; Nevanlinna, 2008; Tyasto et al., 2009; Veselovsky et al., 2009) (Fig. 1, Tables 1 and 2). Later in the 1850s two more observatories were included into the network of regular observations. These were Sitka in Russian Alaska and Peking (now Beijing) in China in the grounds of a Greek Orthodox monastery owned by Russians.

The Russian network of magnetic observations with a large longitudinal extent of about 200 degrees and a latitudinal range of about 20 degrees provided an important contribution of magnetic data acquisition for the scientific community. In addition to magnetic observations a great number of meteorological observations (e.g., atmospheric pressure, temperature, humidity, cloudiness and precipitation) were made continuously during day and night.

Published by Copernicus Publications on behalf of the European Geosciences Union. 


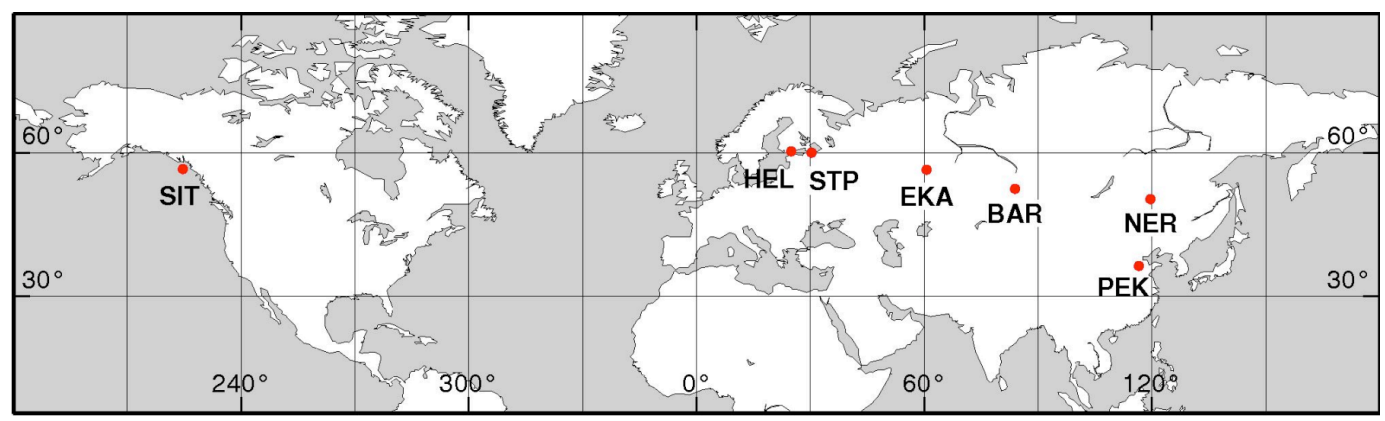

Fig. 1. Geomagnetic observatories used in this study: HEL (Helsinki, Finland) and the Russian observatories STP (St. Petersburg), EKA (Ekaterinburg) (Catherinburg), BAR (Barnaul), NER (Nertchinsk), PEK (Peking, now Beijing) and SIT (Sitka) (see Tables 1 and 2).

Table 1. Geomagnetic observatories in Finland (Helsinki) and Russia used in this study.

\begin{tabular}{lcccc}
\hline \multirow{2}{*}{ Observatory } & \multicolumn{3}{c}{ Geographic coordinates } & \multicolumn{2}{c}{$\begin{array}{c}\text { Corr. geomagn. } \\
\text { coord. (2000) }\end{array}$} \\
& Lat. & Lon. & Lat. & Lon. \\
\hline Helsinki (HEL) & $60^{\circ} 10^{\prime} \mathrm{N}$ & $24^{\circ} 57^{\prime} \mathrm{E}$ & $56.59^{\circ}$ & $102.30^{\circ}$ \\
St. Petersburg (STP) & $59^{\circ} 56^{\prime}$ & $30^{\circ} 18^{\prime}$ & $56.20^{\circ}$ & $106.78^{\circ}$ \\
Ekaterinburg (EKA) & $56^{\circ} 49^{\prime}$ & $60^{\circ} 35^{\prime}$ & $52.74^{\circ}$ & $133.79^{\circ}$ \\
Barnaul (BAR) & $53^{\circ} 20^{\prime}$ & $83^{\circ} 57^{\prime}$ & $49.03^{\circ}$ & $156.68^{\circ}$ \\
Peking (PEK) & $36^{\circ} 57^{\prime}$ & $116^{\circ} 29^{\prime}$ & $31.06^{\circ}$ & $188.90^{\circ}$ \\
Nertchinsk (NER) & $51^{\circ} 19^{\prime}$ & $119^{\circ} 36^{\prime}$ & $45.78^{\circ}$ & $192.39^{\circ}$ \\
Sitka (SIT) & $57^{\circ} 06^{\prime}$ & $224^{\circ} 42^{\prime}$ & $59.77^{\circ}$ & $280.20^{\circ}$ \\
\hline
\end{tabular}

Mainly due to Kupffer's initiative a full-scale permanent magnetic and meteorological observatory was founded in Helsinki (Finland) in 1838 as a part of Helsinki University (e.g., Nevanlinna, 2004, 2005) (Table 1). Kupffer and the first director of the observatory, J. J. Nervander (1805-1848), were in close co-operation in organizational matters and observatory practices. The observatory was located about $300 \mathrm{~km}$ west of the westernmost Russian observatory St. Petersburg (Fig. 1). Today, observations in the Helsinki observatory are continuing at the Nurmijärvi observatory $\left(60.5^{\circ} \mathrm{N}\right.$; $24.6^{\circ} \mathrm{E}$ ) belonging to the Finnish Meteorological Institute. The instrumentation and observational routines in Helsinki were similarly to those in the Russian observatories. The Helsinki observatory started its operations in 1844 and they continued, largely unchanging, with the same magnetic instrumentation for almost 70 years until 1912 (Nevanlinna, 2004).

In 1849 the magnetic and meteorological observations in Russia were reorganized under the Main Physical Observatory established in the same year. Kupffer was appointed the director of the Observatory and a member of the Russian Science Academy. All magnetic and meteorological observations have been published since 1837 by Kupffer and his successors first in the series of Annuaire magnétique et météorologique du corps des ingénieurs des mines de Russie
(1837-1846) and later in Annales de l'observatoire physique central de Russie (1847-1899). The earliest volumes were published separately in Russian for domestic use and in French (later in German) for the international scientific community. Each yearbook volume comprises several hundreds of printed pages with tables of magnetic and meteorological observations and their explanations. Note, that the yearbooks (1837-1913) of the Russian meteorological and magnetic data with background meta-data information, have been converted into pdf pictures by the Library of NOAA (http:// docs.lib.noaa.gov/rescue/data_rescue_russia.html). Original Russian yearbooks have been preserved, in more or less complete collections, and they are available in libraries of several countries that were in co-operation in magnetism and meteorology with Russia in the 19th century.

The magnetic and meteorological observatories initiated by Kupffer were reorganized after Kupffer's death in 1865 when Heinrich Wild (1833-1902) from Switzerland was nominated to the director of the Main Physical Observatory in 1868. The focus of the operations was changed from magnetism to meteorological observations collected at several tens of sites in Russia. Magnetic observations started again in 1870 , after a pause of several years, but mainly in St. Petersburg only. Visual magnetic observations there were replaced by a three-component photographic recording system but the old Gaussian type of variometers remained as backup instruments (Wild, 1872). Magnetic observations stopped in St. Petersburg in 1877 and in the next year the observatory started its observations at a new site Pavlovsk located some $30 \mathrm{~km}$ southeast from St. Petersburg. The operations in Pavlovsk continued until the World War II when the observatory was totally destroyed in the turmoil of the war.

Regular magnetic observations stopped in Nertchinsk, Barnaul, Peking and Sitka in the early 1860s (see Table 2) but continued in Ekaterinburg after a pause until the 1920s (see Golovkov et al., 1983). The Sitka observatory area was transferred to the possession of the USA when Russia sold Alaska in 1867. The new Sitka observatory started its operations in 1901 as a part of the US magnetic observatory network. 
Table 2. Magnetic data availability of Russian observatory data 1837-1869 based on recordings of Gaussian type of unifilar $(D)$ and bifilar $(H)$ variometers.

\begin{tabular}{|c|c|c|c|c|c|c|}
\hline Year & STP $^{\mathrm{a}}$ & EKA & BAR & NER & SIT & $\mathrm{PEK}^{\mathrm{b}}$ \\
\hline 1837 & $\dagger, \mathrm{D}$ & $\dagger, \mathrm{D}$ & - & - & - & - \\
\hline 1838 & $\dagger, \mathrm{D}$ & $\dagger, \mathrm{D}$ & $\dagger, \mathrm{D}$ & - & - & - \\
\hline 1839 & $\dagger, \mathrm{D}$ & $\dagger, \mathrm{D}$ & $\dagger, \mathrm{D}$ & - & - & - \\
\hline 1840 & $\dagger, \mathrm{D}$ & $\dagger, \mathrm{D}$ & $\dagger, \mathrm{D}$ & - & - & - \\
\hline 1841 & $\mathrm{x}$ & $\mathrm{x}-$ & $\mathrm{x}-$ & $\mathrm{x}-$ & - & - \\
\hline 1842 & $\mathrm{x}$ & $\mathrm{x}$ & $\mathrm{x}$ & $\mathrm{x}$ & - & - \\
\hline 1843 & $\mathrm{x}$ & $\mathrm{x}$ & $\mathrm{x}$ & $\mathrm{x}$ & - & - \\
\hline 1844 & $\mathrm{x}$ & $\mathrm{x}$ & $\mathrm{x}$ & $\mathrm{x}$ & - & - \\
\hline 1845 & $\mathrm{x}$ & $\mathrm{x}-$ & $\mathrm{x}$ & $\mathrm{x}-$ & - & - \\
\hline 1846 & $x-$ & $\dagger$ & $\dagger$ & - & - & - \\
\hline 1847 & $\mathrm{x}$ & $\dagger$ & $\dagger$ & $x-$ & - & - \\
\hline 1848 & $\mathrm{x}$ & $\dagger$ & $\dagger$ & $\mathrm{x}, \mathrm{D}$ & - & - \\
\hline 1849 & $\mathrm{x}$ & $\mathrm{x}-$ & $\mathrm{x}$ & $\mathrm{x}$ & - & - \\
\hline 1850 & $\mathrm{x}$ & $\mathrm{x}$ & $\mathrm{x}$ & $\mathrm{x}$ & $\dagger$ & - \\
\hline 1851 & $\mathrm{x}$ & $\mathrm{x}$ & $\mathrm{x}-$ & $\mathrm{x}, \mathrm{Bi}$ & $\dagger$ & $x-$ \\
\hline 1852 & $\mathrm{x}$ & $\mathrm{x}$ & $\mathrm{x}$ & $\mathrm{x}$ & $\dagger$ & $\mathrm{x}$ \\
\hline 1853 & $\mathrm{x}$ & $\mathrm{x}$ & $\mathrm{x}$ & $\mathrm{x}$ & - & $\mathrm{x}$ \\
\hline 1854 & $\mathrm{x}$ & $\mathrm{x}$ & $\mathrm{x}$ & $\mathrm{x}$ & - & $\mathrm{x}$ \\
\hline 1855 & $\mathrm{x}$ & $\mathrm{x}$ & $\mathrm{x}$ & $\mathrm{x}$ & - & $\mathrm{x}$ \\
\hline 1856 & $\mathrm{x}$ & $\mathrm{x}$ & $\mathrm{x}$ & $\mathrm{x}$ & $\dagger, \mathrm{D}$ & - \\
\hline 1857 & $\mathrm{x}$ & $\mathrm{x}$ & $\mathrm{x}$ & $\mathrm{x}$ & $\dagger, \mathrm{D}$ & - \\
\hline 1858 & $\mathrm{x}$ & $\mathrm{x}$ & $\mathrm{x}$ & $\mathrm{x}$ & $\dagger, \mathrm{D}$ & - \\
\hline 1859 & $\mathrm{x}$ & $\mathrm{x}$ & $\mathrm{x}$ & $\mathrm{x}$ & $\dagger, \mathrm{D}$ & - \\
\hline 1860 & $\mathrm{x}$ & $\mathrm{x}$ & $\mathrm{x}$ & $\mathrm{x}$ & $\dagger, \mathrm{D}$ & - \\
\hline 1861 & $\mathrm{x}$ & $\mathrm{x}$ & $\mathrm{x}$ & $\mathrm{x}$ & $\dagger, \mathrm{D}$ & - \\
\hline 1862 & $\mathrm{x}$ & $\mathrm{x}$ & $\mathrm{x}$ & $\mathrm{x}$ & $\dagger, \mathrm{D}$ & - \\
\hline 1863 & - & $\mathrm{x}, \mathrm{Bi}$ & $\mathrm{x}, \mathrm{Bi}$ & $\mathrm{x}, \mathrm{Bi}$ & $\dagger, \mathrm{D}$ & - \\
\hline 1864 & - & $\mathrm{x}, \mathrm{Bi}$ & $\mathrm{x}, \mathrm{Bi}$ & $\mathrm{x}, \mathrm{Bi}$ & $\dagger, \mathrm{D}$ & - \\
\hline 1865 & - & - & - & - & - & - \\
\hline 1866 & - & - & - & - & - & - \\
\hline 1867 & - & - & - & - & - & - \\
\hline 1868 & - & - & - & - & - & - \\
\hline 1869 & - & - & - & - & - & - \\
\hline
\end{tabular}

x Hourly values of $D$ and $H$, no large gaps, $\mathrm{x}, \mathrm{D}=D$ only $\mathrm{x}$ - Hourly values of $D$ and $H$ but with gaps longer than a month $\dagger$ Hourly values of $D$ and $H$ but without nightly hours, $\uparrow, \mathrm{D}=D$ only Bi Bihourly values of $D$ and $H$

- No data available

${ }^{a}$ In 1870 the recordings were started by photographic variometers in STP

b Now Beijing, China. The observatory was located in the grounds of a Russian monastery.

After Kupffer's death in 1865 the Russian observatory network was partly paralysed for many years and only meteorological observations were carried out. However, a new active era in geomagnetic observations started with outcomes of the First International Polar Year 1882-1883. Many new magnetic observatories were founded in Russia in the 1880s that have been running since then. This progress was greatly promoted by Wild who was also the President of the International Polar Commission.

The science of geomagnetism underwent rapid development during the early decades of the 19th century. Important theoretical and practical advances were achieved. As an example of theoretical contribution was Gauss' concept in 1838 that the Earth as a magnet can be represented as an expansion of spherical harmonic functions. This gave a much more accurate picture of the distribution of the magnetic field than the single dipole field configuration presented by Biot and von Humboldt in 1804 (Cawood, 1977).

H. C. Örsted introduced in 1820 the seminal innovation that magnetism and electricity are a manifestation of a hitherto unknown natural force, electromagnetism (e.g., Stern, 2002). This discovery, soon modified and completed by e.g., Ampère, gave a great impetus for scientific studies of the true character of the origin of the Earth's magnetic field: The Earth would be a huge electromagnet maintaining its magnetic field by induction mechanisms rather than by permanent magnetism proposed by Gilbert in 1600 .

It was known in the early 19th century that regular daily variation of magnetic elements followed the local solar time showing largest deviation near midday. Because the daily temperature maximum was also close to the magnetic one, it was speculated that diurnal magnetic variations are caused by temperature variations through thermally induced earth currents. This was a reason why magnetic and meteorological observations were combined in the same observational programme as was the common practice in the 19th century. However, the observational traditions of simultaneous meteorological observations in many countries go back in time to the late 18th century. The Palatine Meteorological Society in Mannheim, Germany, organized an international programme of synoptic meteorological observations. This was perhaps the most important early undertaking in the branch of meteorology. Almost 40 stations, mostly in Europe, were participating in this enterprise for 15 years (1780-1795) (Cassidy, 1985).

Another foci of interest in the geophysical science of the early 19th century were phenomena that are today called space weather and space climate, that is, transient geomagnetic variations and storms and their morphology in time and space. The concept "magnetic storm" was introduced by von Humboldt in 1808 (Malin and Barraclough, 1991). Kupffer in Kazan near the river Volga in Russia and Arago in Paris made simultaneous observations of magnetic disturbances in the 1820s. They found that great disturbances occur at the same time at both sites although the distance between them was about $50^{\circ}$ in longitude. The reason for this parallelism of magnetic storms remained obscured but later it became evident that the solution may be found in solar circumstances when, in 1852 Sir Edward Sabine discovered that the number 
of sunspots and the appearance of magnetic storms are correlated in the course of the 11-year solar cycle (Stern, 2002). The observations of the great Carrington magnetic storm in 1859 linked a single solar eruption (flare) to terrestrial space weather phenomena including northern lights. Recently, the Carrington storm has regained scientific interest because it was probably the greatest space weather disturbance for centuries (see the special issue on the Carrington storm in the Journal of Advances in Space Research, Vol. 38, 2006, and, e.g., Tsurutani et al., 2003; Cliver and Svalgaard, 2004; Siscoe et al., 2006; Nevanlinna, 2008; Tyasto et al., 2009; Veselovsky et al., 2009).

In this paper we have utilized Russian magnetic observatory data in their original printed yearbooks available in Finnish scientific libraries, that is, for the years 1850-1910. We have photographed the tables containing magnetic observations by using a normal digital camera. Special pattern recognition software was designed for digitizing the pictures into machine-readable form for further data analysis.

This study comprises an analysis of the magnetic results of four Russian observatories for 13 years 1850-1862 (Tables 1 and 2). During that time interval the recordings were continuing on hourly bases (spot readings at every full hour) at all four observatories without any lengthy gaps. Before 1850 there were longer gaps in the observations and many nightly hours were skipped. After 1862 there were no magnetic recordings for about eight years. The period 1850 1862 is thus the most suitable for geomagnetic analysis of the whole Russian observatory activities since 1837 . A preliminary trial has been made for utilizing the pdf pictures compiled by NOAA for 1837-1849 but there were unresolved problems in the proper conversion of pixels to numbers.

Our goal of the analysis of Russian magnetic data is to reconstruct magnetic activity index series that will complement the existing ones from the 19th century: Mayaud's aa-series (e.g., Mayaud, 1980; Menvielle and Berthelier, 1991) 1868and the Helsinki aa-extension 1844-1897 (e.g., Nevanlinna, 2004). The index algorithm applied to the Russian data (Menvielle et al., 1995) (based on hourly values) is the same that has been utilized in the analysis of Helsinki (Finland) magnetic observatory data 1844-1897 (Nevanlinna, 2004).

\section{Magnetic observations}

Regular observations of magnetic field changes with thread suspended magnets started in the Paris observatory in the 1790s. This new type of variometer, developed by Coulomb and Cassini, rapidly superseded pivoted navigational compasses as tools of accurate observatory instruments (see e.g., Chapman and Bartels, 1940; Cawood, 1977). The accuracy of visual magnetic direction readings was later much enhanced by Poggendorff's invention (1826) of the mirrorand-scale method where the distance between the magnet and the observer was several meters. This observation method was adopted by Gauss in the Göttingen observatory and in the observatories belonging to the magnetic observation programme directed by the Magnetic Union.

There were three types of variometers for observing the magnetic field variations in the observatory community: Gauss' unifilar and bifilar magnetometers for declination $(D)$ and horizontal component $(H)$, respectively and Lloyd's magnetic balance for vertical field $(Z)$ variations introduced in the late 1830s (see e.g., Chapman and Bartels, 1940). In the unifilar system the suspension thread was made by silk and was $2-3 \mathrm{~m}$ long. The magnet pointed to the magnetic meridian. In the bifilar system the magnet is kept perpendicular to the magnetic meridian by two long wires made from silver and connected with the torsion head. The D- and $\mathrm{H}-$ magnets were about $60 \mathrm{~cm}$ long weighing about $2 \mathrm{~kg}$. The magnets were put between copper bars for attenuating the unnecessary vibrations of the magnets. The whole recording system was surrounding by a large wooden shelter to prevent the magnets from disturbing air currents in the variation room. The variometers distributed to the observatories were manufactured in Göttingen by the famous instrument maker Moritz Meyerstein (1808-1882) (Hentschel, 2007).

Magnetic balance for recording variations of the Zcomponent was introduced by Humphrey Lloyd (18001881) from the magnetic observatory of Dublin (Ireland) (Barraclough et al., 1992). This device was distributed in many magnetic observatories of the time. However, the baseline stability of the instrument was not good and therefore many observatories abandoned it for long-term use, as was the case in the Russian observatories.

Further information about the variometers described here is given in the yearbook of 1843 of the Russian observatory network (Kupffer, 1843). It contains drawings of the magnetic instruments and detailed explanations of their working principles. Other publications of the 19th century also give presentations of the theory of variometers and geomagnetic instruments (e.g., Gauss and Weber, 1837; Lamont, 1867). For more modern descriptions of historical geomagnetic instruments, see e.g., McConnell (1980), Multhauf and Good (1987), Basso Ricci et al. (1997) and Nevanlinna (1997).

At all observatories given in Table 1 and shown in Fig. 1, the magnetic observations were made on the horizontal field $(H)$ and declination $(D)$. Variations in the magnetic field were observed visually from a scale mounted on a telescope through which the sightings of the magnet were made. Each hourly value was of the mean value of five observations at $15 \mathrm{~s}$ intervals centered on the full hour. The observed quantity is thus a scale reading $\left(S_{\mathrm{D}} S_{\mathrm{H}}\right)$ (in $1 / 24$ inches), which is then converted to relative magnetic field values $\Delta D$ and $\Delta H$. For $D$, the formula is

$\Delta D=\varepsilon_{\mathrm{D}} S_{\mathrm{D}}$,

and for $H$ it is

$\Delta H / H=\varepsilon_{\mathrm{H}} S_{\mathrm{H}}+\alpha\left(t-t_{o}\right)$ 


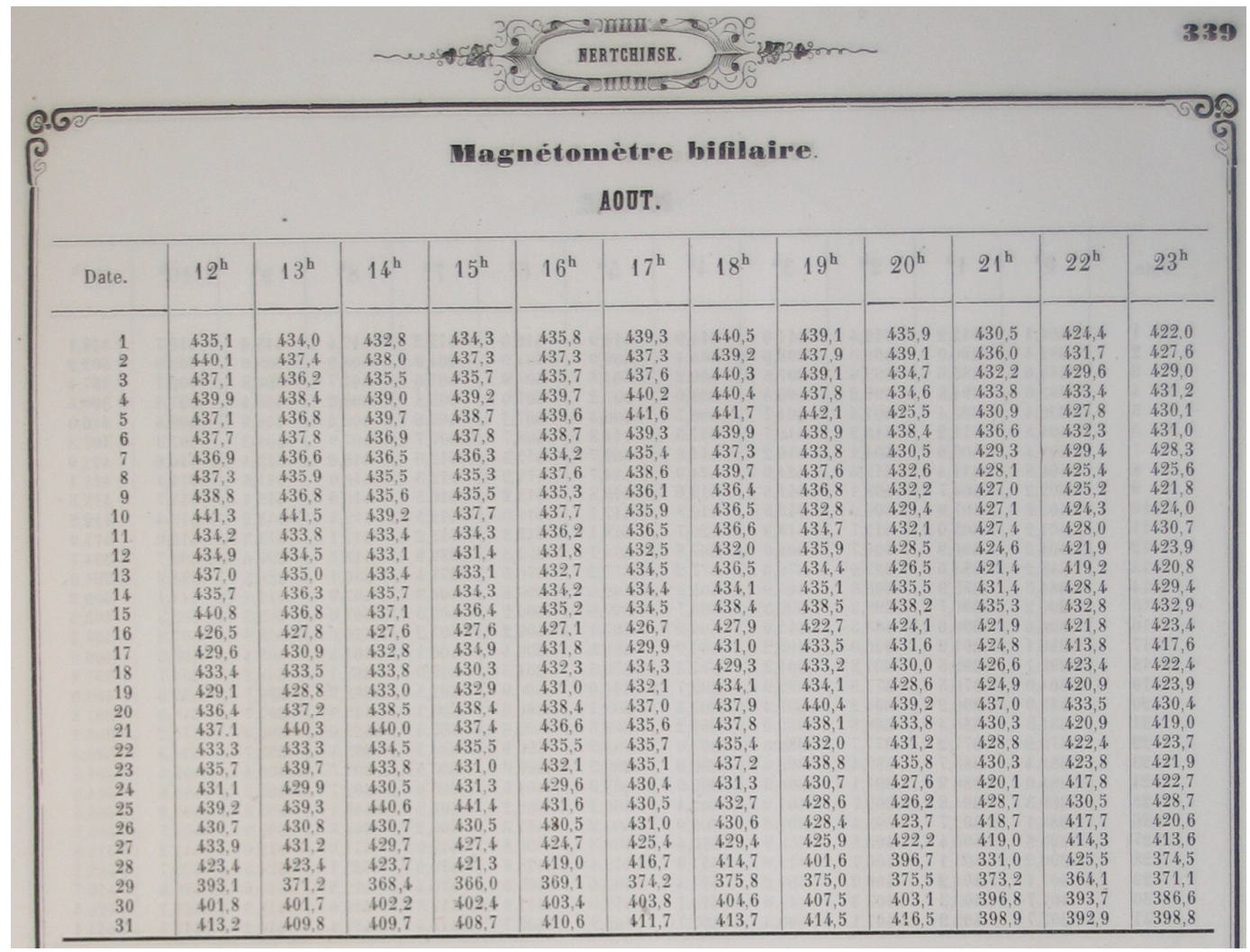

Fig. 2. An example of a part of a yearbook data table. The page is for H-component (Magnétométre bifilaire) from the observatory Nertchinsk August 1859 showing data from 12:00 h to 23:00 h (00:00 h-11:00 h local time). The column on the left gives the dates. Hours are shown on the upper row. Other columns give observed instantaneous hourly values of $H$ in units of 1/24 inch (roughly $1 \mathrm{~mm}$ ) taken from the scale.

where $\varepsilon_{\mathrm{D}}, \varepsilon_{\mathrm{H}}$ are the scale value for the $\mathrm{D}$ - and $\mathrm{H}$-variometer, respectively. $\alpha$ is the temperature coefficient of the bifilar variometer; $t$ the temperature above a reference point $\left(t_{o}\right)$ and $H$ is the local horizontal field intensity. The $H$-magnet was a special layered construction that minimized the temperature effect and thus no temperature corrections were needed (Tyasto et al., 2009). However, Wild (1872) redetermined the scale values in 1870 and found that the temperature coefficient was non-negligibly $7.7 \mathrm{nT} /{ }^{\circ} \mathrm{C}$. In this study we have omitted the temperature correction because most of the data are without temperature information. The scale values of the variometers analysed in the present analysis are given by Nevanlinna (2008) and Tyasto et al. (2009). For more technical details, see Lamont (1867), Kupffer (1843), Nevanlinna and Ketola (1993) and Nevanlinna (1997).

Normally, observations were taken at one-hour intervals but on prearranged term days in 5-min intervals. The termday observations provided the raw material for studies of magnetic storms recorded simultaneously at magnetic observatories over a wide geographical extent.

In the 19th century coordinated magnetic observations were usually made according to the Göttingen astronomical time where $0 \mathrm{~h}$ corresponds to noon and $12 \mathrm{~h}$ is midnight.
The number of days was counted from noon to noon (see e.g., Boteler, 2006; Shea and Smart, 2006). In the Russian yearbooks analysed in this study the time in hourly observations was given in the Göttingen time until 1856 (1857 in St. Petersburg) and later in local solar time (LT). Göttingen time leads by 0.66 hours the present day Universal Time (UT). In this study the time of the magnetic data series has been converted in UT.

\section{Digitization of tabulated observatory data}

Observatory yearbooks were photographed by using an ordinary digital camera for the years 1850-1862 from four observatories (STP, EKA, BAR and NER) shown in Table 1. Each double page contains data from two months arranged in rows and columns as depicted in Fig. 2. The layout of the yearbook tables was kept the same from 1841 to 1864 . This made it possible to convert the jpg pictures to digits using the same computer program without changes from year to year. Each double page of a jpg picture consists of $2500 \times 2000$ pixels. Single columns, rows and digits were identified from the intensity difference between the white background and dark printed area. Each digit was recognized by the maximum 

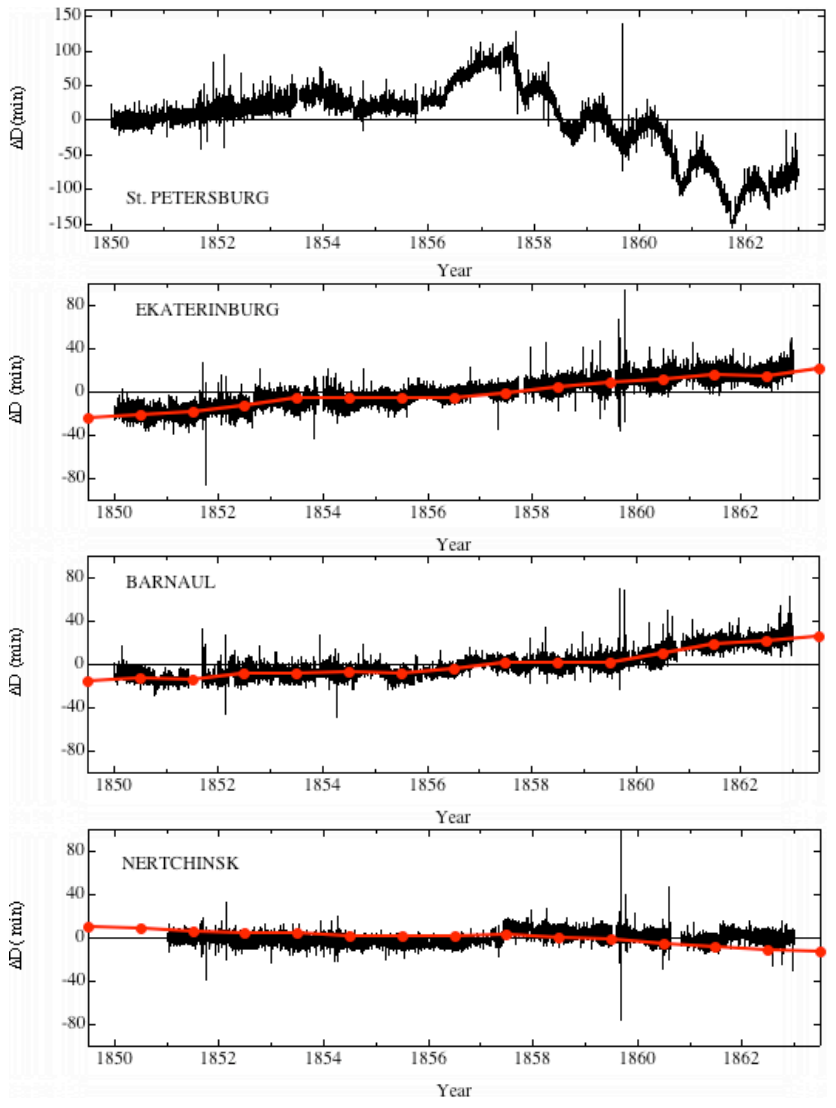

Fig. 3. Black: Hourly values (spot readings) of magnetic declination $(\Delta D)$ (in minutes) for 1850-1862. Spikes represent magnetically disturbed storm hours. Red: Secular variation of $D$ from Golovkov et al. (1983).

correlation between digit pixels and those of a known test number. Errors in number identifications were only a few percentage, but a considerable amount of errors was found to be typing misprints in the original yearbook tables. In the visual quality control of the data series suspicious single spikes in hourly values were correlated with the data from other observations and clearly erroneous data points were discarded. The present study comprises about 450000 hourly values of $D$ and $H$ for 13 years from $1850-1862$.

In recent years much effort has been done for rescuing historical magnetic data according to the resolutions of the International Association of Geomagnetism and Aeronomy (IAGA). Recent examples of this kind of work are the digitisation project of historical magnetograms of the UK observatories back to 1848 (Clarke et al., 2009) and a similar task in France back to 1883 (Fouassier and Chulliat, 2008).
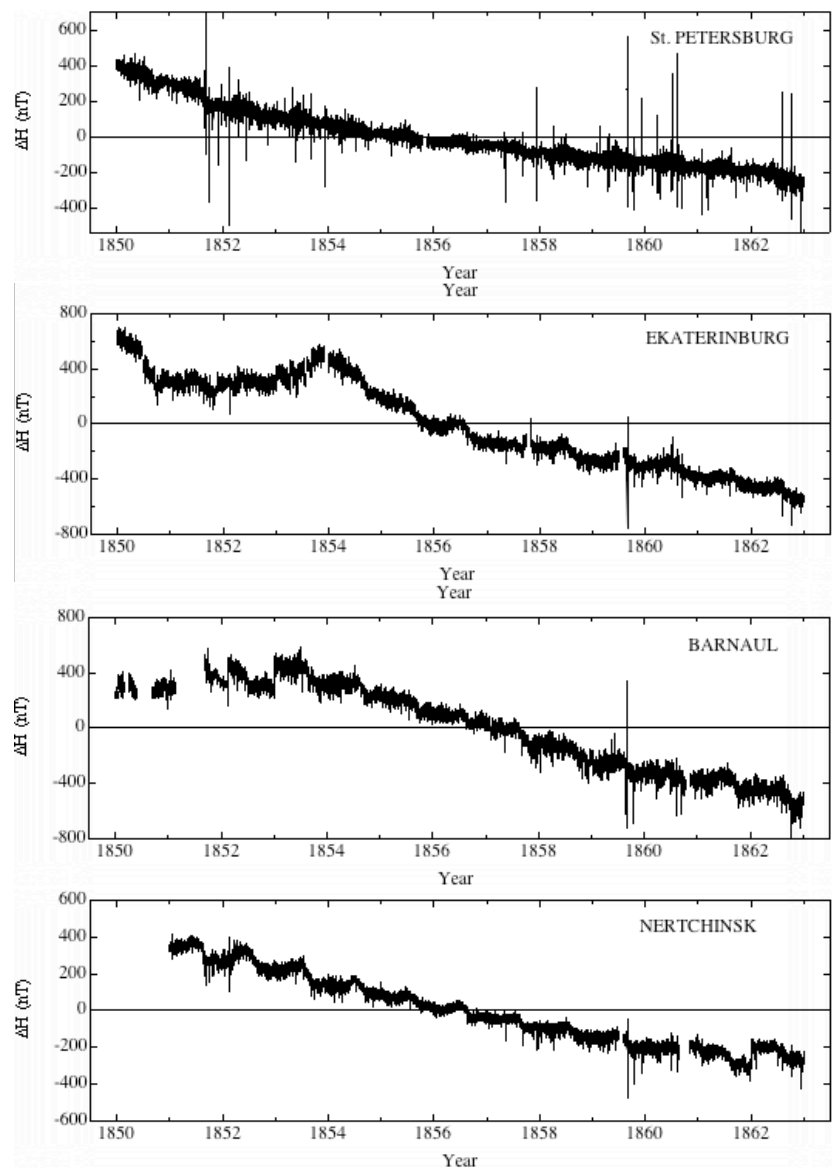

Fig. 4. Hourly values (spot readings) of the magnetic horizontal component $(\Delta H)$ in nT 1850-1862. The high spikes here and in Fig. 3 in 1859 (August-September) are signatures of the famous Carrington magnetic storm.

\section{Time series of magnetic data 1850-1862}

The scale value readings of the $D$ - and $H$-variometers can be converted to magnetic field variations by using Eqs. (1) and (2) (without the temperature correction term for $H$ ). The conversion factors needed in Eqs. (1) and (2) for each observatory are given by Nevanlinna (2008).

Figure 3 shows times series of hourly records of the Dcomponent 1850-1862 at STP, EKA, BAR and NER. Spikes represent magnetically stormy hours of which the Carrington storm sequence in August-September 1859 is the most prominent.

The construction of the D-variometer was such that the magnet points to the magnetic north direction. As this direction changes slowly from year to year due to the secular variation, the D-magnet follows the secular change as well as the high frequency transient variations. This can be seen in Fig. 3 where the annual secular change is depicted together with the hourly values. Values of secular change were obtained 


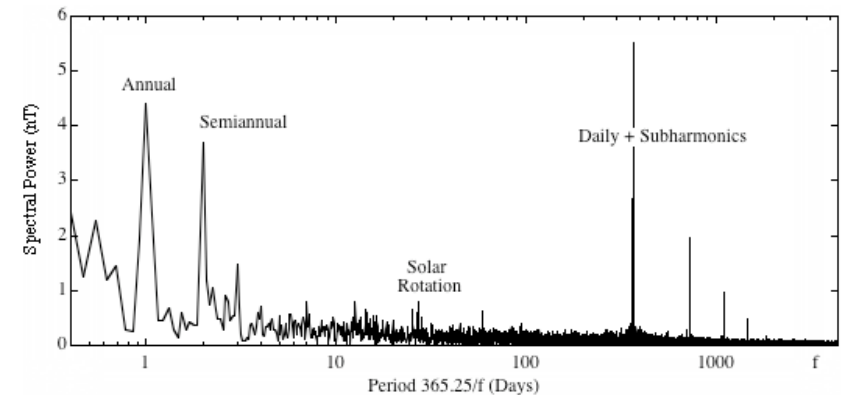

Fig. 5. FFT-spectrum of the hourly horizontal field values $(\Delta H)$ at STP showing regular waves in annual, semiannual, solar rotation and daily variation with its subharmonics.

from the data compilation by Golovkov et al. (1983) containing annual mean values of the magnetic field observed at world magnetic observatories (these values are also available at the WDC for Geomagnetism in Edinburgh, UK). The annual secular variation data from the Russian observatories are based on absolute measurements carried out in the observatories roughly once per month. Secular variation changes systematically at each observatory but their trends are different because of the large distances between the observatories. At STP the systematic secular variation trend breaks down at about 1855 after which there have been quasi-periodic variations of unknown reason until the end of the observation series in 1862.

Figure 4 shows the time series of hourly values of the Hcomponent 1850-1862. They show similar systematic variations and trends as the corresponding series of $D$. However, in $H$ the systematic change from year to year is not due to the secular variation but is caused probably in slow weakening in the magnetic moment of the magnets and changes in the torsional forces in the bifilar recording devise.

As can be seen in Figs. 3 and 4 the occurrence of major magnetic storms is clearly higher in STP than in other Russian observatories located at lower latitudes (see Table 1). STP is a subauroral station and the frequency of great magnetic storms is therefore greater than in the more southern sites.

Figure 5 shows a FFT-spectrum analyses (STP, Hcomponent) of hourly values $1850-1862$. Spectral spikes can be seen in annual, semiannual, (weak) solar rotation (27d), and daily variation $(24 \mathrm{~h})$. The daily variation peak splits to three subharmonics at 12,8 , and $6 \mathrm{~h}$, respectively.

\section{Magnetic activity}

Terrestrial magnetic activity is a signature of space weather conditions in the Earth's magnetosphere ultimately governed by solar activity. In space climate studies utilizing geomagnetic observations, magnetic indices are widely used for characterizing space weather and climate changes in different time scales. Indices are either local for a single site, such
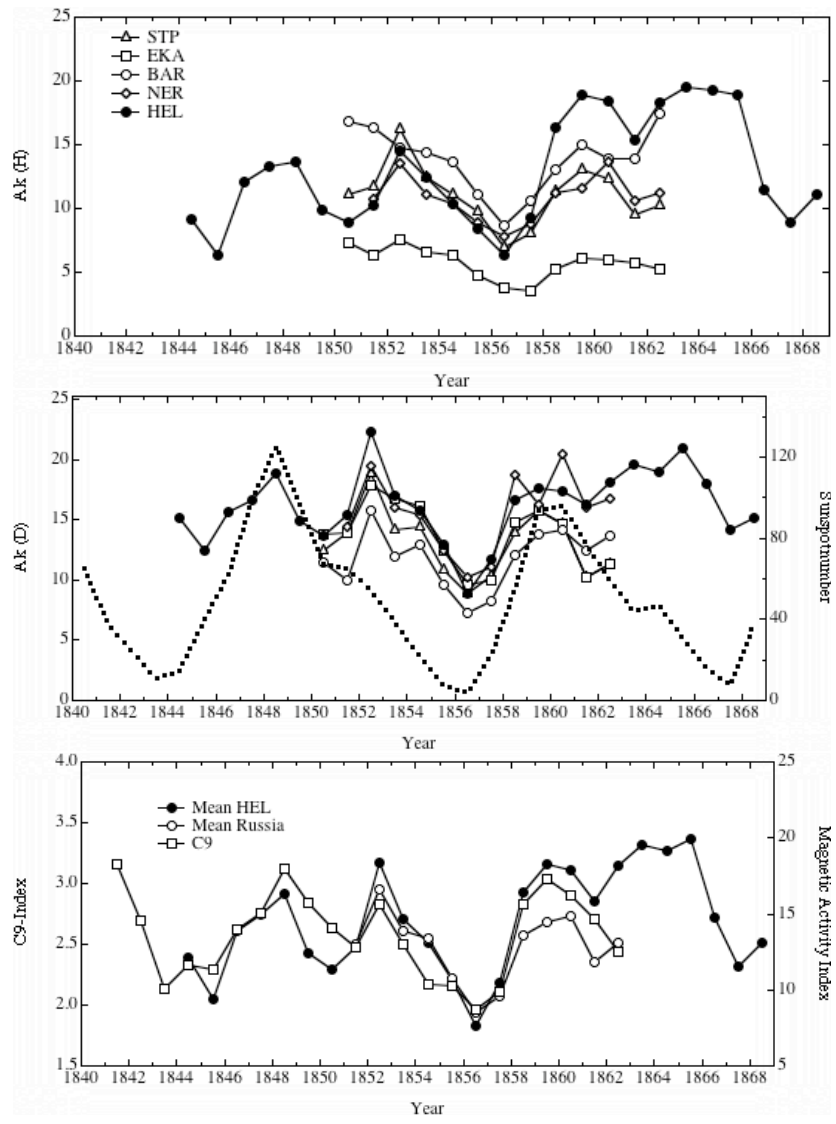

Fig. 6. Upper panel: Annual means of daily magnetic activity index (Ak) from Russian observatories and Helsinki (HEL) as calculated from the D-component. Mid-panel: Activity indices as calculated from the H-component. Dotted line: Annual means of sunspot numbers. Lower panel: Mean values of activity indices based on H- and D-data for Helsinki (HEL) (dots), the Russian stations (Mean Russia) (circles) and the $C 9$-activity index calculated from STP (squares).

as the three-hour K-index, or global, for example Dst, Ap or aa based on magnetic data from several observatories (Rangarajan, 1989). In space climate studies, an important requirement is the long time coverage and the homogeneity of the index series. The longest available global index series is the three-hour aa-index belonging to the $\mathrm{K}$-index family (Menvielle and Berthelier, 1991). It is based on magnetic recordings of two almost antipodal observatories in Australia and UK. The aa-series covers the years since 1868 . The Dstindex have been reconstructed since 1958 and Ap since 1932.

Recently, new indices (e.g., Inter-Hour Variability Index, IHV) have been introduced when old magnetic data from the 19th and early 20th centuries have been utilized in various studies concerning, e.g., the long-term trends in the magnetic activity or reconstruction of solar wind parameters for space climate analysis (e.g., Svalgaard and Cliver, 2007; Rouillard et al., 2007; Mursula and Martini, 2007). 

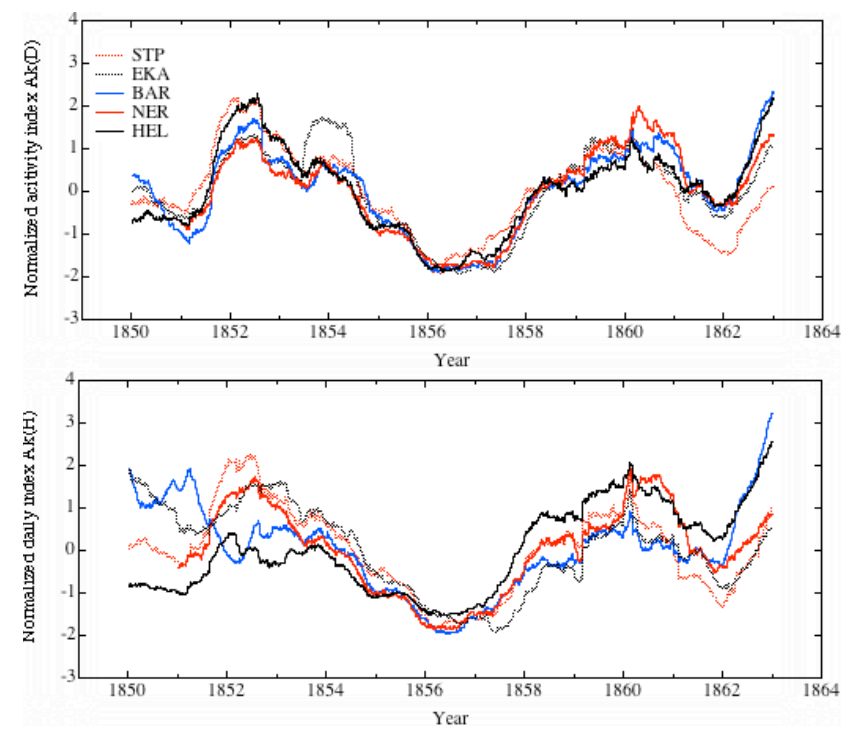

Fig. 7. Upper panel: 365 d running means of normalized daily activity indices (Ak) as calculated from the D-component. There are data from four Russian observatories together with the Helsinki data (see Table 1). Lower panel: Same as above but for the H-component.

The K-indices were originally hand-scaled from analogue magnetograms. However, there are several algorithms that are now used for automatic production of the K-index from digital magnetic 1-min data (e.g. Menvielle et al., 1995). In an earlier study (Nevanlinna, 2004) we applied the so-called FMI K-index method (Sucksdorff et al., 1991) for calculations of the activity index from Helsinki data. In this procedure the regular daily variation $\left(S_{\mathrm{r}}\right)$ is removed by fitting a superposition of harmonic waves for each 24-h data series before the $\mathrm{K}$-indices were determined from the residual. Because the Helsinki data consists of discrete hourly readings, the activity index series must be calibrated to correspond to a continuous magnetic recording. This was done by adjusting the percentage occurrence rate of 3-h K-indices in each of 10 bins $(0,1, \ldots, 9)$ to be the same as in the corresponding distribution from the present day Nurmijärvi observatory. Nurmijärvi is close $(40 \mathrm{~km})$ to Helsinki, and it can be thus expected that space weather conditions are similar at both observatories. The calibration was achieved by varying the Helsinki $K=9$ lower limit ( $K 9$ ). The best correspondence with Nurmijärvi was attained by fixing $K 9=200 \mathrm{nT}$ for both D- and H-variations. The $K=9$ limit at Nurmijärvi is $750 \mathrm{nT}$.

Long-term averages of the Helsinki index and the corresponding global aa are in good mutual agreement. In monthly means, the correlation coefficient for the overlapping time period $1868-1897$ is about 0.9 . Although the Helsinki activity index is not exactly equivalent to the global aa-index, they can be used as an (pseudo) extension of the aa-index for about two solar cycles 1844-1868 (Nevanlinna and Kataja, 1993; Nevanlinna, 2004).
The same procedure of index calculations as described above for the Helsinki data was applied to the Russian magnetic observatory data $(H$ and $D)$ 1850-1862. It was found that the lower limit (in nT) of the $K=9$ for each observatory and for both $\mathrm{H}$ - and D-components were as follows: STP 140, EKA 115, BAR 100, and NER 90. The limit values decrease with decreasing magnetic latitude. The three-hour $\mathrm{K}$-indices were converted to daily values (Ak). Their annual means (Helsinki activity data included) can be seen in Fig. 6 and daily running means $(365 \mathrm{~d})$ in Fig. 7 . The gaps in the daily series were filled by a linear interpolation. Short jumps in the original time series were not corrected, and there are thus apparent activity spikes at the discontinuities. However, in the annual means shown in Figs. 6 and 7 they smooth out.

The activity period studies here overlaps partly the solar cycles 9 and 10 for the years 1843-1867. The solar maxima were in 1848 and 1860, and minima in 1843, 1856 and 1867. The Russian activity index series show a minimum at 1856 coinciding with the solar cycle minimum. There were two geomagnetic activity maxima at 1852 and 1860 shown in the Russian data series and one more in about 1866 in the Helsinki series. During both solar cycles 9 and 10 there can be seen the Gnevyshev gaps (Gnevyshev, 1967) lowered magnetic activity period closely after the sunspot maximum. The first activity maximum in the cycle 9 occurred in 1848 simultaneously with the sunspot maximum as can be seen in the Helsinki activity series (Figs. 6 and 7). The corresponding activity maximum during the cycle 10 was at about 1860 .

The time variation of the Russian activity series $\operatorname{Ak}(H)$ and $\operatorname{Ak}(D)$ (Fig. 6) follows rather closely the corresponding curves obtained from the Helsinki data except the $\operatorname{Ak}(H)$ curve of EKA, which is anomalously low for reasons unknown. However, if the activity indices are normalized by subtracting the mean value from each individual time series and dividing the residual by the standard deviation, we get activity curves depicted in Fig. 7 showing good agreement of the time variations. The data in Fig. 7 are $365 \mathrm{~d}$ moving averages of daily values of $\operatorname{Ak}(H)$ and $\operatorname{Ak}(D)$. One can see that the scatter in the $\operatorname{Ak}(D)$-curves is smaller than in $\operatorname{Ak}(H)$ and there is a temporary deviation of EKA in $\operatorname{Ak}(D)$ around 1854.

The activity index (Ak) curves derived here from the Russian observatories (1850-1862) as well as the corresponding data from the Helsinki observatory have been completed for the period 1841-1862 by another activity index called $C 9$ (for its definition, see Rangarajan, 1989). It has been determined by Zosemovich (1981) using the daily recordings of STP. The $C 9$ index measures the daily amplitude of the magnetic disturbances ( $D$ or $H$ ) after subtracting the regular magnetic field variation. It thus closely related to the Akindex studied here. Figure 6 (lower panel) shows the annual means of the $C 9$ together with the mean values of annual $\operatorname{Ak}(H)$ and $\operatorname{Ak}(D)$ from four Russian stations and the same from Helsinki. One can see that the time variations of the different activity indices are rather similar. When Helsinki 
Table 3. Extended aa-index series from Helsinki four Russian observatory data $1841-1868$.

\begin{tabular}{ccl}
\hline Year & Index & Data sources \\
\hline 1841 & 15.3 & STP \\
1842 & 12.9 & STP \\
1843 & 10.1 & STP \\
1844 & 11.7 & HEL+STP \\
1845 & 9.9 & HEL+STP \\
1846 & 13.3 & HEL+STP \\
1847 & 14.1 & HEL+STP \\
1848 & 15.7 & HEL+STP \\
1849 & 13.0 & HEL+STP \\
1850 & 12.0 & HEL+STP \\
1851 & 12.9 & HEL+Russia \\
1852 & 17.5 & HEL+Russia \\
1853 & 14.3 & HEL+Russia \\
1854 & 13.2 & HEL+Russia \\
1855 & 10.7 & HEL+Russia \\
1856 & 7.9 & HEL+Russia \\
1857 & 10.1 & HEL+Russia \\
1858 & 14.9 & HEL+Russia \\
1859 & 16.4 & HEL+Russia \\
1860 & 16.4 & HEL+Russia \\
1861 & 13.8 & HEL+Russia \\
1862 & 15.6 & HEL+Russia \\
1863 & 20.0 & HEL \\
1864 & 19.2 & HEL \\
1865 & 19.9 & HEL \\
1866 & 14.8 & HEL \\
1867 & 11.6 & HEL \\
1868 & 13.1 & HEL \\
\hline & &
\end{tabular}

activity index is compared with that of the mean Russian numbers, the difference is relatively small. The annual $C$ 9numbers from STP can be converted to the Ak-scale. Combining all indices together we get an index series for 18411868 that gives a more robust extension of the global aaindex series than only using data from a single site (Helsinki) as presented in the papers by Nevanlinna and Kataja (1993) and Nevanlinna (2004) (see Table 3). The difference between the Helsinki series and mean Russian stations is less than 2 Ak-unit in annual means during the overlapping time interval of 13 years.

\section{Conclusions}

Spot readings of hourly magnetic data ( $\mathrm{H}-$ and $\mathrm{D}-$ components) were digitized from Russian yearbook tables for the years 1850-1862 from four observatories. The compilation of the Russian magnetic data for 1841-1849 is un- der work. The jpg pictures for the digitization were taken by a normal digital camera. The database obtained consists of about 900000 single data points. The time series of hourly magnetic values reveal slow secular variations (declination only) as well as transient and regular geomagnetic variations of external origin. The quality of the observations is reliable and the data can be used for space weather analysis and deriving activity indices for different time periods.

Daily Ak-indices were calculated using the index algorithm that has been earlier applied to 19th century data from Helsinki (Finland) as well as modern magnetic observatory recordings. The activity index series derived from the Russian data is consistent with the Helsinki series. These data can contribute to the extension of the global magnetic index series aa (1868 onwards) and other activity index series derived from historical magnetic data. However, there are clearly long-term (months to years) variations (Figs. 3 and 4) in the data due to instrumental causes although their effect on the homogeneity of the derived daily index series is not serious as long as only longer term averages such as annual mean values are considered.

The Russian geomagnetic observatory network established by Kupffer in the 1830 s was a great success and of scientific benefit to the geomagnetic community of the 19th century. Kupffer was a skilful organizer of the practical work done in magnetic and meteorological observations. He was also deeply experienced in the instrumentation needed in various observations. The magnetic and meteorological data collected at the observatories was treated, checked and printed in yearbook tables rather soon (2-3 years) after each observation year. There was a large number of data accumulated from year to year. Annually more than 50000 observations of magnetic and meteorological parameters were carried out at each observatory and printed in the yearbooks. Thanks to the efforts of the observatory staff supervised by Kupffer there are now available good quality (in the standards of the 19th century) magnetic spot data with hourly or bihourly resolution for many decades for space weather and other solar-terrestrial studies.

\section{Appendix A}

The magnetic variation data, hourly values of $H$ and $D$ for 1850-1862, from the Russian observatories STP, EKA, BAR and NER (Figs. 3 and 4) can be obtained from the wwwsite of the Finnish Meteorological Institute on request by the authors.

Acknowledgements. Thanks are given to Anneli Ketola for her contributions in the data treatment, Pekka Turunen and Kim Frisk for taking the jpg pictures of yearbook tables, Esko Puheloinen, Pirjo Martikainen and Ritva Hänninen for helping in the search of yearbook material in archives.

Topical Editor R. Nakamura thanks E. Clarke and another anonymous referee for their help in evaluating this paper. 


\section{References}

Barraclough, D. R., Clark, T. D. G., Cowley, S. W. H., et al.: 150 years of magnetic observatories: Recent research on world data, Surv. Geophys., 13, 47-88, 1992.

Basso Ricci, M., Cafarella, L., Meloni, A., and Tucci, P.: Two centuries of geomagnetic instruments in Italy (1740-1971), Ist. Nazion. Geof., 234 p., 1997.

Boteler, D. H.: Comment on time conventions in the recordings of 1859, Adv. Space Res., 38, 301-303, 2006.

Cassidy, D. C.: Meteorology in Mannheim: The Palatine Meteorological Society, Sudhoffs Archiv, 69, 8-25, 1985.

Cawood, J.: Terrestrial magnetism and the development of international collaboration in the early nineteenth century, Ann. Sci., 34, 551-572, 1977.

Chapman, S. and Bartels, J.: Geomagnetism, Vol. I \& II. Oxford, Clarendon Press, 1940.

Clarke, E., Flower, S., Humphries, T., et al.: The digitisation of observatory magnetograms. Poster presentation (V02/715) at the 11th Scientific meeting of IAGA, Sopron, Hungary, 2009.

Cliver, E. W. and Svalgaard, L.: The 1859 solar-terrestrial disturbance and the current limits of extreme space weather activity, Solar Phys., 224, 407-422, doi:10.1007/s11207-005-4980-z, 2004.

Fouassier, D. and Chulliat, A.: Extending backwards to 1883 the French magnetic hourly data series. Paper presented at the XIIIth IAGA Workshop on Geomagnetic Observatory Instruments, Data Acquisition and Processing, Golden, Colorado, USA, 9-18 June 2008.

Gauss, C. F. and Weber, W.: Beobachtungen des magnetischen Vereins im Jahre 1836, Göttingen, 1837.

Gnevyshev, M. N.: On the 11-years cycle of solar activity, Solar Phys., 1, 107-120, 1967.

Golovkov, V. P., Kolomitzeva, G. I., Konyashchenko, L. P., and Semyonova, G. M.: Summary of annual means at world magnetic observatories, Vol. XVI, IZMIRAN, 1983.

Hentschel, K.: Gauss, Meyerstein and Hanoverian metrology, Ann. Sci., 64, 41-75, 2007.

Kupffer, A.: Annuaire magnétique et météorologique - Année $1841,1843$.

Lamont, J.: Handbuch des Geomagnetismus, Leipzig, 468 p., 1867.

Malin, S. R. C. and Barraclough, D. R.: Humboldt and the Earth's magnetic field, Q. J. Roy. Astr. Soc., 32, 279-293, 1991.

McConnell, A.: Geomagnetic instruments before 1900, Harriet Wynter Ltd, London, 75, 1980.

Mayaud, P. N.: Derivation, meaning, and use of geomagnetic indices, Amer. Geophys. Union, Washington, D.C., 1980.

Menvielle, M. and Berthelier, A.: The $K$-derived planetary indices: Description and availability, Rev. Geophys., 29, 413-432, 1991.

Menvielle, M., Papitashvili, N., Häkkinen, L., and Sucksdorff, C.: Computer production of $K$ indices: review and comparison of methods, Geophys. J. Int., 123, 866-886, 1995.

Multhauf, R. P. and Good, G.: A brief history of geomagnetism and a catalog of the collections of the National Museum of American History, Smithsonian Stud. Hist. Technology, No. 48, 1987.
Mursula, K. and Martini, D.: New indices of geomagnetic activity at test: Comparing the correlation of the analogue $a k$ index with the digital $A_{h}$ and IHV indices at the Sodankylä station, Adv. Space Res., 40, 1105-1111, 2007.

Nevanlinna, H.: Gauss' $H$-Variometer at the Helsinki Magnetic Observatory (1844-1912), J. Geomagn. Geoelectr., 49, 1209-1216, 1997.

Nevanlinna, H.: Results of the Helsinki magnetic observatory 1844-1912, Ann. Geophys., 22, 1691-1704, 2004, http://www.ann-geophys.net/22/1691/2004/.

Nevanlinna, H.: Founding Father of Finnish Geomagnetic Research. Transaction of AGU, EOS, 86, 325-327, 2005.

Nevanlinna, H.: On geomagnetic variations during the AugustSeptember storms of 1859, Adv. Space Res., 42, 171-180, 2008.

Nevanlinna, H. and Ketola, A.: Magnetic results from Helsinki magnetic-meteorological observatory. Part III, Geophys. Publ. Finn. Met. Inst., 33, 1-194, 1993.

Rangarajan, G. K.: Indices of geomagnetic activity, in: Geomagnetism, edited by: Jacobs, J. A., Acad. Press, 3, 323-384, 1989.

Rouillard, A. P., Lockwood, M., and Finch, I.: Centennial changes in the solar wind speed and in the open solar flux, J. Geophys. Res., 112, A05103, doi:10.1029/2006JA012130, 2007.

Shea, M. A. and Smart, D. F.: Compendium of the eight articles on the "Carrington event" attributed to or written by Elias Loomis in the American Journal of Science, 1859-1861, Adv. Space Res., 38, 304-312, 2006.

Siscoe, G., Crooker, N. U., and Clauer, C. R.: Dst of the Carrington storm of 1859, Adv. Space Res., 38, 173-179, 2006.

Soffel, H.: Johann von Lamont: A pioneer in geomagnetism, Transaction of AGU, EOS, 87, 247-249, 2006.

Stern, D. P.: A millenium of geomagnetism, Rev. Geophys., 40, 4, doi:10.1029/2000RG000097, 2002.

Sucksdorff, C., Pirjola, R., and Häkkinen, L.: Computer production of $K$-indices based on linear elimination, Geophys. Trans., 36, 333-345, 1991.

Svalgaard, L. and Cliver, E. W.: Long-term geomagnetic indices and their use in inferring solar wind parameters in the past, Adv. Space Res., 40, 1112-1120, 2007.

Tsurutani, B. T., Gonzales, W. D., Lakhna, G. S., and Alex, S.: The extreme magnetic storm of 1-2 September 1859, J. Geophys. Res., 108, A7, doi:10.1029/2002JA009504, 2003.

Tyasto, M. I., Ptitsyna, N. G., Veselovsky, I. S., and Yakovchouk, O. S.: Extremely strong geomagnetic storm in September 2-3, 1859 , according to the archived data of observations at the Russian network, Geomagn. Aeron., 49, 153-162, 2009.

Veselovsky, I. S., Mursula, K., Ptitsyna, N. G., Tyasto, M. I., and Yakovchouk, O. S.: Sporadic and recurrent geomagnetic disturbances in 1859-1860 according to the archived data from Russian network of stations, Geomagn. Aeron., 49, 163-168, 2009.

Wild, H.: Annalen des physikalischen Centralobservatoriums, Jahrgang 1870, 1872.

Zosemovich, I. D.: Geomagnetic activity and stability of solar corpuscular radiation, Science Press, Moscow, USSR, 86 p., 1981 (in Russian). 